\title{
Factors associated with the technical quality of root canal fillings performed by undergraduate dental students in a Malaysian Dental School
}

\author{
Choon Yoong Wong ${ }^{1}$, Yan Xia Liaw ${ }^{1}$, Jhiew Zhan Wong ${ }^{1}$, Lee Chian Chen ${ }^{1}$, Abhishek Parolia ${ }^{1}$, Allan Pau \\ ${ }^{1}$ International Medical University, School of Dentistry, Division of Clinical Dentistry, Kuala Lumpur, Malaysia
}

\begin{abstract}
Aim: A retrospective clinical audit was carried out on records of endodontic treatment performed by dental undergraduates. The audit was performed to evaluate the technical quality of root canal fillings performed by dental undergraduates and determine the associated factors. Methods: 140 records of patients who had received root canal treatment by dental undergraduates were evaluated through periapical radiographs by two examiners $(\kappa=0.74)$. The root canal fillings had their quality evaluated according to extent, condensation and presence of procedural mishap. Possible factors associated with technical quality such as tooth type, canal curvature, student level and quality of record keeping were evaluated. Data were statistically analyzed using chi-square test $(p<0.05)$. Results: Among the 140 root-filled teeth, acceptable extent, condensation and no-mishap were observed in $72.1 \%$, $66.4 \%$ and $77.9 \%$ cases respectively. Overall, the technical quality of 68 (48.6\%) root-filled teeth was considered acceptable. Overall, non-acceptable root canal fillings were significantly more likely to be observed in molars (69.2\%), moderately and severely curved canals $(71.4 \%)$ and junior students $(61.5 \%)$. There was no association between acceptable root canal fillings and quality of record keeping. Conclusions: The technical quality of root canal fillings was acceptable in $48.6 \%$ cases and it was associated with tooth type, degree of canal curvature and student seniority.
\end{abstract}

Keywords: Endodontics. Root Canal Therapy. Education.

\section{Introduction}

Endodontic treatment encompasses procedures designed to maintain the health of all or part of the dental pulp. When the dental pulp is diseased, endodontic treatment aims at preserving healthy periradicular tissues. However, if apical periodontitis occurs, the treatment aims restoring the periradicular tissue health.

The purpose of endodontic treatment is to disinfect the entire root canal system and maintain asepsis ${ }^{1}$. The European Society of Endodontology stated that an appropriate endodontic treatment involves the following parameters: exposure of a good quality preoperative radiograph, administration of local anesthesia, isolation of tooth, preparation of access cavity, determination of working length, shaping, cleaning and obturation of the root canal system ${ }^{1}$. There is substantial evidence that the technical quality of root canal fillings has a significant impact on the outcome of the treatment and long-term retention 
of endodontically treated teeth ${ }^{1}$. Many studies reported that root canal fillings placed within 0-2 $\mathrm{mm}$ of the radiographic apex are associated with lesser chances of radiographic and clinical failures than those that are under-filled or over-filled ${ }^{2-6}$.

Clinical audit is defined as a quality improvement process that seeks to improve patient care and outcomes by systematic review of care against explicit criteria and the implementation of change. The use of clinical audit in endodontic treatment has been widely reported $^{5,7-14}$.

This study was a clinical audit on technical quality of root canal fillings performed by undergraduates. The aims of this study were to evaluate the quality of root canal fillings performed by dental undergraduates in a Malaysian Dental School and to determine factors associated with the technical quality of root canal fillings.

\section{Material and methods}

The present study was restricted to patients who attended the School of Dentistry, International Medical University, Kuala Lumpur, Malaysia, for root canal treatment. A retrospective clinical audit was carried out on the records of endodontic treatment performed only by undergraduate students. All 142 electronic records of endodontic treatment performed by dental undergraduates from January 2011 to April 2013 were retrieved and printed. Inclusion criterion of this study was endodontic treatment completed by dental undergraduates. Incomplete endodontic treatment and records without post-operative radiographs were excluded. Two records were excluded due to incomplete treatment and missing postoperative radiograph respectively. The remaining 140 records fulfilled the inclusion criteria. Two fourth year dental undergraduates carried out the audit after undergoing training in clinical audit, which consisted of:

- A 2-h seminar on the principles and practice of clinical audit.

- Desktop research on criteria for assessing the technical quality of root canal fillings and quality of record keeping.

- Development of audit checklist form and protocol for auditing the records.

- Training on radiographic evaluation of root canal fillings by an endodontist.

\section{Root Canal Treatment Procedure}

The dentist first examined patients who attended IMU Oral Health Centre seeking for treatment and then referred these cases to undergraduate students or endodontic specialists based on the complexity of the tooth/root canal and economic concern of the patients. The subjects were patients who had a specific endodontic disease needing emergency treatment. After thorough clinical examination and considering the technical difficulties related to root canal therapy, the endodontic staff allotted these patients to different cohorts of undergraduates based on their seniority and competency level.

The chief concern of the patient was obtained together with patient's medical, dental, pain history. Appropriate investigations were carried out to come to a diagnosis. All root canal procedures were performed using a rubber dam and aseptic technique. Access cavities were prepared using endodontic access burs (Dentsply
Maillefer, Ballaigues, Switzerland). The working lengths (1 mm short of the radiographic apex) were established using electronic apex locators and reconfirmed radiographically.

The hybrid technique was used for shaping and cleaning procedures. The coronal two-thirds of the canals were prepared sequentially using Gates Gliden burs, (Dentsply Maillefer) and K-Flex file (Dentsply Maillefer). The apical third was instrumented to the master apical file $1 \mathrm{~mm}$ short from the radiographic apex. Root canals were further instrumented with step-back enlargement to three sizes larger than the master apical file. Finally, circumferential filing was done to complete the shaping of the root canal. 2\% sodium hypochlorite (Clorox Company, Broadway, Oakland, CA, USA), saline (to flush sodium hypochlorite and prevent any interaction in between sodium hypochlorite and EDTA) and $18 \%$ ethylenediaminetetraacetic acid (EDTA, Ultradent Products Inc., South Jordan, UT, USA) were used as irrigants.

All patients were treated in multiple visits and non-setting calcium hydroxide (Calcicur, Voco Gmbh, Cuxhaven, Germany) as an intracanal dressing and reinforced zinc oxide temporary cement (IRM, Dentsply Caulk, Milford, DE, USA) or Cavit (3M ESPE, St. Paul, MN, USA) as a temporary restorative materials were used between appointments.

In the subsequent visits all root canals were filled using guttapercha points with AH plus (Dentsply Maillefer) root canal sealer using lateral compaction technique. Following, all root canals were sealed with glass ionomer cement (GC Corporation, Tokyo, Japan) and thereafter the most suitable post- endodontic coronal restorations (amalgam/composite/post and core) were placed after assessing the amount of remaining tooth structure.

\section{Evaluation of the technical quality of root canal fillings}

Three periapical radiographs were examined for each root canal filling: pre-operative, working length determination and post-operative. Two examiners evaluated independently all the radiographs. Radiographs were examined in the form of full screen images that could be enhanced and zoomed in on the computers. If disagreement in interpretation occurred between the examiners, the radiographs were re-evaluated until an agreement was reached. Kappa value for inter-examiner agreement was 0.74. The technical quality of root canal fillings was evaluated according to condensation of root canal fillings, extent of root canal fillings and presence of procedural mishaps (Table 1$)^{8}$. For a multi-rooted tooth, all canals were evaluated simultaneously and an overall score was given to the tooth (e.g. technical quality of a multi-rooted tooth was considered acceptable only when the technical quality of all the root canals was acceptable).

\section{Possible factors associated with the technical quality of root canal fillings}

Anatomical characteristics of tooth: For each root-treated tooth, the tooth type and complexity (root canal curvature) were assessed. The complexity (root canal curvature) was determined based on the pre-operative radiographs according to the Schneider's classification of curvature ${ }^{15}$. Tooth with moderate $\left(10-20^{\circ}\right)$ and severe curvature $\left(25-70^{\circ}\right)$ canals were combined and compared against tooth with straight canal $\left(5^{\circ}\right.$ or less). 
Student seniority: Third and fourth year undergraduates were combined and compared to fifth year undergraduates.

Quality of the record keeping of endodontic treatment: Evaluation of quality of record keeping was based on the records of each endodontic treatment performed by undergraduate students. All the records were audited independently by two examiners against the set of criteria that had been previously developed accordingly to the European Society of Endodontology guideline ${ }^{1}$. The presence or absence of recording of each criterion (total $=17$ ) was observed: use of an electric pulp test, use of local anesthesia, name of local anesthesia, dosage of local anesthesia, use of rubber dam isolation, working length, reference point of working length, size of initial apical file, size of master apical file, applied intracanal dressing, medication prescribed including analgesics and antibiotics, size of master cone, pre-operative radiograph, working length radiograph, master cone radiograph, post-operative radiograph and advice on final restoration in the follow-up visit.

\section{Statistical analysis}

Data were entered into SPSS 18.0 (SPSS, Inc., Chicago, IL, USA) for analysis. The frequency distributions of the technical quality of root canal fillings were calculated. Chi-square tests were performed to determine associations between the technical quality of root canal fillings and possible associated factors (e.g. tooth type, root canal curvature, student seniority and quality of record keeping). The significance level was set at $\mathrm{p}<0.05$.

\section{Results}

\section{Technical quality of root canal fillings}

The present study reviewed the records 140 root-filled teeth.
The distribution of this sample according to the tooth type and student seniority is in Table 2. Sixty-five (46.4\%) teeth were treated by third and fourth year undergraduates and the remaining by the fifth year undergraduates. The most commonly treated tooth types were molars $(37.1 \%)$, followed by premolars $(32.9 \%)$, incisors $(23.6 \%)$ and canines $(6.4 \%)$. The condensation of root filling was acceptable in $93(66.4 \%)$ cases, extent was acceptable in 101 $(72.1 \%)$ cases and no mishaps were observed in $109(77.9 \%)$ cases (Table 3). Overall, the technical quality of 68 (48.6\%) of all 140 root-filled teeth was considered acceptable (Table 3 ).

\section{Possible factors associated with the technical quality of root canal fillings}

Among the different tooth types, mishaps were significantly more likely to be observed in molars $(32.7 \%$, Table 4) compared to premolars $(8.7 \%, \mathrm{p}<0.05)$. Overall non-acceptable root canal fillings were significantly more likely to be noted in molars $(69.2 \%)$ compared to other tooth types $(p<0.01)$. Under- and over-extended of root canal fillings were significantly more likely to be observed in moderately and severely curved canals $(47.6 \%)$ compared to straight canals $(24.4 \%, \mathrm{p}<0.05)$. Overall non-acceptable root canal fillings were significantly more likely to be observed in moderately and severely curved canals $(71.4 \%)$ compared to straight canals $(47.9 \%, \mathrm{p}<0.05)$. According to student seniority, non-acceptable condensation was more common among third and fourth year students $(49.2 \%)$ compared to fifth year students $(20.0 \%, \mathrm{p}<0.01)$. Similarly, non-acceptable extent was more common among junior students $(36.9 \%)$ compared to senior students $(20.0 \%, \mathrm{p}<0.05)$. Overall non-acceptable root canal fillings were significantly associated with junior students $(61.5 \%)$ compared to senior students $(42.7 \%, \mathrm{p}<0.05)$.

Table 1 - Criteria used to assess technical quality of root canal fillings.

\begin{tabular}{|c|c|c|}
\hline Variables & Criteria & Definition \\
\hline \multirow[t]{2}{*}{ Condensation } & Acceptable & $\begin{array}{l}\text { No void identified in root canal filling or between } \\
\text { root canal filling and root canal walls }\end{array}$ \\
\hline & Non-acceptable & $\begin{array}{l}\text { Presence of void in root canal filling or between root } \\
\text { canal filling and root canal walls }\end{array}$ \\
\hline \multirow[t]{3}{*}{ Extent } & Acceptable & $\begin{array}{l}\text { Root canal filling material is within the root canal } \\
\text { system and within } 2 \mathrm{~mm} \text { of the radiographic apex }\end{array}$ \\
\hline & Under-filled & $\begin{array}{l}\text { Root canal filling material is }>2 \mathrm{~mm} \text { short of the } \\
\text { radiographic apex }\end{array}$ \\
\hline & Over-filled & $\begin{array}{l}\text { Root canal filling material is extruded beyond the } \\
\text { radiographic apex }\end{array}$ \\
\hline \multirow[t]{5}{*}{ Mishap } & No mishap & No mishap identified \\
\hline & Ledge & $\begin{array}{l}\text { Root canal filling is at least } 1 \mathrm{~mm} \text { shorter than } \\
\text { the working length and is deviated from the } \\
\text { original canal curvature }\end{array}$ \\
\hline & Perforation & $\begin{array}{l}\text { Apical termination of filled canal is different } \\
\text { from the original canal terminus or root canal } \\
\text { filling material is extruded through the apical } \\
\text { foramen }\end{array}$ \\
\hline & $\begin{array}{l}\text { Separation of } \\
\text { instruments }\end{array}$ & Separated instrument identified \\
\hline & Others & Other mishaps identified \\
\hline \multirow[t]{2}{*}{ Overall } & Acceptable & $\begin{array}{l}\text { Acceptable condensation and extent of root canal } \\
\text { filling with no mishap }\end{array}$ \\
\hline & Non-acceptable & $\begin{array}{l}\text { Non-acceptable condensation and/or non- accept- } \\
\text { able extent of root canal filling with/without mishap }\end{array}$ \\
\hline
\end{tabular}


Table 2 - Distribution of teeth in the sample.

\begin{tabular}{lccccc}
\hline Student seniority & Incisors & Canines & Premolars & Molars & Total (\%) \\
$3^{\text {rd }}$ and $4^{\text {th }}$ & 19 & 3 & 24 & 19 & $65(46.4 \%)$ \\
$5^{\text {th }}$ & 14 & 6 & 22 & 33 & $75(53.6 \%)$ \\
\hline Total $(\%)$ & $33(23.6 \%)$ & $9(6.4 \%)$ & $46(32.9 \%)$ & $52(37.1 \%)$ & $140(100.0 \%)$ \\
\hline
\end{tabular}

\section{Discussion}

The key findings of this retrospective study were that the technical quality of root canal fillings performed by the fifth year dental undergraduates were superior to the third and fourth year undergraduates, and the overall technical quality was better in anterior teeth and teeth with straight canals irrespective of student seniority. Overall, the technical quality of root canal fillings performed by dental undergraduates in this study was considered acceptable in nearly half the sample. This result is lower than those reported for Scottish ${ }^{13}$, Lithuanian ${ }^{9}, \operatorname{Irish}^{11}$, Greek $^{10}$, Iranian ${ }^{16}$, Turkish ${ }^{17}$ and Serbian students ${ }^{18}$, but better when compared to Turkish $^{8}$, French ${ }^{12}$, Jordanian ${ }^{19}$, Saudi Arabian ${ }^{7}$ and Spanish students ${ }^{20}$. Wide variations in proportions of acceptable root canal fillings have been reported in the literature. They may be related to the different criteria used in evaluation, size and types of selected sample and the training the students received. For example, the Lithuanian study ${ }^{9}$ did not take procedural mishap into account for evaluation of the technical quality and the findings were only based on condensation and extent of root canal fillings. Lynch $\&$ Burke (2006) reported that $63.0 \%$ of root canal llings were technically acceptable ${ }^{11}$. However, only single-rooted teeth were included in their study as compared to the present study, which evaluated the technical quality performed on both single-rooted and multi-rooted teeth.

In the present study, non-acceptable root canal fillings were more common in the molars compared to the incisors, canines and premolars. The reason for this was the high incidence of procedural mishaps in the molars. This is consistent with results reported by Balto et al. ${ }^{7}$, Moussa-Badran et al. ${ }^{12}$, and Moradi et al. ${ }^{21}$. The high incidence of procedural mishaps may be attributed to the anatomy of molars (e.g. multiple root canals and greater canal curvatures) and difficulty to have adequate coronal access during the procedure ${ }^{21}$. The results also highlighted that nonacceptable root canal fillings were more common in teeth with curved canals ${ }^{18}$. Under-filled and over-filled root canal fillings occurred more frequently in teeth with curved canals and this may be attributed to the failure to realize canal curvature before preparation of the root canal system, leading to internal and external transportation, over-preparation, and straightening of the curved canals. In consequence, the loss of apical stop may result in over-filling of root canals. To improve the technical quality of root canal fillings in the molars and teeth with curved canals, endodontic training must emphasize the difficulties of treating molars and teeth with curved canals. Increase in pre-clinical laboratory training and addition of seminars would be beneficial for students to familiarize with necessary procedures and precautions required for managing molars and teeth with curved canals. The use of dental magnification such as magnifying loupes and operating microscopes while performing molar endodontics would enhance visualization of the treatment field and increase accuracy of the endodontic procedure ${ }^{22}$. In addition; the use of rotary instruments may be considered, especially for molar endodontics ${ }^{20,23}$. However, it is not used by our undergraduate students.

Table 3 - Acceptable and non-acceptable root canal fillings performed by undergraduate students.

\begin{tabular}{llc}
\hline Variables & Criteria & Definition \\
& Acceptable & $93(66.4 \%)$ \\
& Non-acceptable & $47(33.6 \%)$ \\
\hline Extent & Acceptable & $101(72.1 \%)$ \\
& Under-filled & $19(13.6 \%)$ \\
& Over-filled & $20(14.3 \%)$ \\
\hline Mishap & No mishap & $109(77.9 \%)$ \\
& Ledge & $12(9.3 \%)$ \\
& Perforation & $16(11.4 \%)$ \\
& Separation of instruments & $1(0.7 \%)$ \\
& Others & $1(0.7 \%)$ \\
\hline Overall & Acceptable & $68(48.6 \%)$ \\
& Non-acceptable & $72(51.4 \%)$ \\
\hline
\end{tabular}

Table 4 - Non-acceptable root canal fillings according to tooth type, complexity, student seniority, and quality of record keeping.

\begin{tabular}{llccccc}
\hline & Total & $\begin{array}{c}\text { Total of overall } \\
\text { non-acceptable }\end{array}$ & $\begin{array}{c}\text { Non-acceptable } \\
\text { condensation }\end{array}$ & $\begin{array}{c}\text { Under-filled and } \\
\text { over-filled }\end{array}$ & $\begin{array}{c}\text { Mishap } \\
\text { Tooth type }\end{array}$ \\
& Incisors & 33 & $16(48.5 \%)^{*}$ & $9(27.3 \%)$ & $8(24.2 \%)$ & $8(24.2 \%)^{* *}$ \\
& Canines & 9 & $2(22.2 \%)$ & $0(0.0 \%)$ & $1(11.1 \%)$ & $2(22.2 \%)$ \\
& Premolars & 46 & $18(39.1 \%)$ & $16(34.8 \%)$ & $10(21.7 \%)$ & $4(8.7 \%)$ \\
& Molars & 52 & $36(69.2 \%)$ & $22(42.3 \%)$ & $20(38.5 \%)$ & $17(32.7 \%)$ \\
\hline Complexity & Straight & 119 & $57(47.9 \%)^{* *}$ & $39(32.8 \%)$ & $29(24.4 \%)^{* *}$ & $25(21.0 \%)$ \\
& Moderate and severe & 21 & $15(71.4 \%)$ & $8(38.1 \%)$ & $10(47.6 \%)$ & $6(28.6 \%)$ \\
\hline Student seniority & $3^{\text {rd }}$ and $4^{\text {th }}$ & 65 & $40(61.5 \%)^{* *}$ & $32(49.2 \%)^{*}$ & $24(36.9 \%)^{* *}$ & $14(21.5 \%)$ \\
& $5^{\text {th }}$ & 75 & $32(42.7 \%)$ & $15(20.0 \%)$ & $15(20.0 \%)$ & $17(22.7 \%)$ \\
\hline Quality of record keeping & Good $\dagger$ & 69 & $33(47.8 \%)$ & $20(29.0 \%)$ & $19(27.5 \%)$ & $14(20.3 \%)$ \\
& Poor $\dagger$ & 71 & $39(54.9 \%)$ & $27(38.0 \%)$ & $20(28.2 \%)$ & $17(23.9 \%)$ \\
\hline
\end{tabular}

${ }^{*} p<0.01 .{ }^{* *} p<0.05$. $†$ good quality of record keeping (11-17 criteria recorded in record); poor quality of record keeping (<11 criteria recorded in record). 
The technical quality of root canal fillings performed by fifth year dental undergraduates was significantly better than by the third and fourth year undergraduates. On one hand, this is to be expected as the fifth year dental undergraduates are more experienced; however, all patients treated by undergraduates should expect the same high quality endodontic treatment regardless the student's seniority. To minimize the percentage of non-acceptable root canal fillings performed by third and fourth year dental undergraduates, closer supervision is recommended as well as case selection according to the degree of difficulty ${ }^{24}$. Simple cases of endodontic treatment (e.g. anterior teeth and teeth with straight canals) should be treated by third and fourth year dental undergraduates whilst a little bit more complex cases (including molar teeth with a slight root curvature) should be treated by the fifth year dental undergraduates. Moreover, teeth with moderate or high level of difficulty should be referred to specialists. This will allow the third and fourth year dental undergraduates to gain adequate competency in managing simple cases prior to performing more complex cases of endodontic treatment.

In this retrospective study, only half of the clinical records kept by dental undergraduates met the criteria of good record keeping, despite implementation of general guidelines on record keeping for endodontic treatment in the dental clinic. This finding emphasizes the need to reinforce the guidelines on record keeping. Although the present results showed that the quality of record keeping had no significant association with the technical quality of root canal fillings, inadequate record keeping may increase the opportunities for potential litigation by the patients ${ }^{25}$. Therefore it is mandatory for the dental undergraduates to record details of the procedure performed to avoid medicolegal issues.

In all cases performed by dental undergraduates, the working length measurement (i.e $1 \mathrm{~mm}$ before the apex) was established using electronic apex locators and reconfirmed radiographically, which is routinely used in most of the dental schools $^{26}$. The instruments used for canal preparation were stainless steel hand K Flex files and Gates Glidden burs (Dentsply Maillefer). Canal preparation was carried out using a combination of crown down and step back technique. This technique has been shown to be useful for teaching dental undergraduates ${ }^{11} .2 \%$ sodium hypochlorite (Clorox) and 18\% EDTA (Ultradent Products Inc.) were used as irrigants. Alternate use of sodium hypochlorite and EDTA hwas found to be very effective in removing the smear layer from the root canals ${ }^{27,28}$. Calcium hydroxide (Calcicur, Nordiska Dental $\mathrm{AB}$, Angelholm, Sweden) was used as an intra-canal medicament that provides antimicrobial activity and prevents recontamination of the root canal system ${ }^{29,30}$. Lateral compaction technique with gutta-percha points and AH plus (Dentsply Maillefer, USA) root canal sealer was used to obturate all the canals, a technique used in other countries ${ }^{2,8,31}$.

There are a few limitations in this retrospective study. The sample size is relatively small and the radiographical analysis does not entirely reflect the technical quality of root canal fillings because it is not a direct indication of the disinfection quality. Besides that, a single periapical radiograph only provides a twodimensional image. Therefore it is sometimes difficult to separate superimposed anatomical structures (e.g. multiple root canals) while evaluating the radiographs ${ }^{16}$.
In conclusion, the technical quality of root canal fillings performed by dental undergraduates was acceptable in nearly half the cases. The results have highlighted points that should be considered during the case selection for undergraduate students and also in the teaching of endodontics. Factors found to be associated with the technical quality of root canal fillings were tooth type, root canal curvature and student seniority.

\section{References}

1. European Society of Endodontology. Quality guidelines for endodontic treatment: consensus report of the European Society of Endodontology. Int Endod J. 2006 Dec;39(12):921-30.

2. Hayes SJ, Gibson M, Hammond M, Bryant ST, Dummer PM. An audit of root canal treatment performed by undergraduate students. Int Endod J. 2001 Oct;34(7):501-5.

3. Kerekes K, Tronstad L. Long-term results of endodontic treatment performed with a standardized technique. J Endod. 1979 Mar;5(3):83-90.

4. Marques MD, Moreira B, Eriksen HM. Prevalence of apical periodontitis and results of endodontic treatment in an adult, Portuguese population. Int Endod J. 1998 May;31(3):161-5.

5. Petersson K, Petersson A, Olsson B, Hakansson J, Wennberg A. Technical quality of root fillings in an adult Swedish population. Endod Dent Traumatol. 1986 Jun;2(3):99-102.

6. Ray HA, Trope M. Periapical status of endodontically treated teeth in relation to the technical quality of the root filling and the coronal restoration. Int Endod J. 1995 Jan;28(1):12-8.

7. Balto H, Al Khalifah S, Al Mugairin S, Al Deeb M, Al-Madi E. Technical quality of root fillings performed by undergraduate students in Saudi Arabia. Int Endod J. 2010 Apr;43(4):292-300. doi: 10.1111/j.13652591.2009.01679.x

8. Er O, Sagsen B, Maden M, Cinar S, Kahraman Y. Radiographic technical quality of root fillings performed by dental students in Turkey. Int Endod J. 2006 Nov;39(11):867-72.

9. Kelbauskas E, Andriukaitiene L, Nedzelskiene I. Quality of root canal filling performed by undergraduate students of odontology at Kaunas University of Medicine in Lithuania. Stomatologija. 2009; 11(3):92-6.

10. Khabbaz MG, Protogerou E, Douka E. Radiographic quality of root fillings performed by undergraduate students. Int Endod J. 2010 Jun;43(6):499508. doi: 10.1111/j.1365-2591.2010.01706.x.

11. Lynch $C D$, Burke FM. Quality of root canal fillings performed by undergraduate dental students on single-rooted teeth. Eur J Dent Educ. 2006 May;10(2):67-72.

12. Moussa-Badran S, Roy B, Bessart du Parc AS, Bruyant M, Lefevre B, Maurin JC. Technical quality of root fillings performed by dental students at the dental teaching centre in Reims, France. Int Endod J. 2008 Aug;41(8):679-84. doi: 10.1111/j.1365-2591.2008.01417.x.

13. Pettigrew LK, Jauhar $S$, Lynch CD, Savarrio L, Carrotte P, Hannigan A. An audit of the quality of root canal treatments performed by undergraduate dental students on single-rooted teeth in Glasgow dental hospital and school. Eur J Prosthodont Restor Dent. 2007 Jun;15(2):72-6.

14. De Quadros 11, Gomes BP, Zaia AA, Ferraz CC, Souza-Filho FJ. Evaluation of endodontic treatments performed by students in a Brazilian Dental School. J Dent Educ. 2005 Oct;69(10):1161-70.

15. Schneider SW. A comparison of canal preparations in straight and curved root canals. Oral Surg Oral Med Oral Pathol. 1971 Aug;32(2):271-5. 
16. Yavari H, Samiei M, Shahi S, Borna Z, Abdollahi AA, Ghiasvand N, Shariati G. Radiographic evaluation of root canal fillings accomplished by undergraduate dental students. Iran Endod J. 2015;10(2):127-30.

17. Unal GC, Kececi AD, Kaya BU, Tac AG. Quality of root canal fillings performed by undergraduate dental students. Eur J Dent. 2011 Jul;5(3):324-30.

18. Vukadinov T, Blažić L, Kantardžić I, Lainović T. Technical quality of root fillings performed by undergraduate students: a radiographic study. ScientificWorldJournal. 2014 Jan 28;2014:751274. doi: 10.1155/2014/751274.

19. Barrieshi-Nusair KM, Al-Omari MA, Al-HiyasatAS. Radiographic technical quality of root canal treatment performed by dental students at the Dental Teaching Center in Jordan. J Dent May. 2004;32(4):301-7.

20. Román-Richon S, Faus-Matoses V, Alegre-Domingo T, Faus-Llácer VJ. Radiographic technical quality of root canal treatment performed ex vivo by dental students at Valencia University Medical and Dental School, Spain. Med Oral Patol Oral Cir Bucal. 2014 Jan;19(1):e93-7.

21. Moradi S, Gharechahi M. Radiographic quality of root canal treatment performed by 6(th) year undergraduate students in Mashhad, Iran. Dent Res J (Isfahan). 2014 May;11(3):364-9.

22. Carr GB, Murgel CA. The use of the operating microscope in endodontics. Dent Clin North Am. 2010 Apr;54(2):191-214. doi: 10.1016/j. cden.2010.01.002.
23. Abu-Tahun I,Al-Rabab'ah MA, Hammad M, KhraisatA. Technical quality of root canal treatment of posterior teeth after rotary or hand preparation by fifth year undergraduate students, The University of Jordan. Aust Endod J. 2014 Dec;40(3):123-30. doi: 10.1111/aej.12069.

24. Webber J. Risk management in clinical practice. Part 4. Endodontics. $\mathrm{Br}$ Dent J. 2010 Aug 28;209(4):161-70. doi: 10.1038/sj.bdj.2010.721.

25. Ilgüy D, Ilgüy M, Fisekçioglu E, Ersan N, Tanalp J, Dölekoglu S. Assessment of root canal treatment outcomes performed by Turkish dental students: results after two years. J Dent Educ. 2013 Apr;77(4):502-9.

26. Qualtrough AJ, Dummer PM. Undergraduate endodontic teaching in the United Kingdom: an update. Int Endod J. 1997 Jul;30(4):234-9.

27. Haapasalo M, Shen Y, Qian W, Gao Y. Irrigation in endodontics. Dent Clin North Am. 2010 Apr;54(2):291-312. doi: 10.1016/j.cden.2009.12.001.

28. Violich DR, Chandler NP. The smear layer in endodontics - a review. Int Endod J. 2010 Jan;43(1):2-15. doi: 10.1111/j.1365-2591.2009.01627.x.

29. Kawashima N, Wadachi R, Suda H, Yeng T, Parashos P. Root canal medicaments. Int Dent J. 2009 Feb;59(1):5-11.

30. Siqueira JF Jr, Lopes HP. Mechanisms of antimicrobial activity of calcium hydroxide: a critical review. Int Endod J. 1999 Sep;32(5):361-9.

31. Elsayed RO, Abu-Bakr NH, Ibrahim YE. Quality of root canal treatment performed by undergraduate dental students at the University of Khartoum, Sudan. Aust Endod J. 2011 Aug;37(2):56-60. doi: 10.1111/j.17474477.2010.00273.x. 